\section{Marking Time on Metrication}

IT is hard to understand how the British Government has allowed itself to get into difficulties over the plan to adopt the metric system in Britain. Until a month ago, everything seemed to be going smoothly--the Board of Trade had announced approval for the change, and had defined a broad timetable; the British Standards Institution, charged with the detailed task of organizing the change, seemed well on top of its job. Within the government departments, the Standing Joint Committee on Metrication made little secret of its plans, and they seemed sensible enough. Industry, while not welcoming change any more enthusiastically than usual, was broadly in approval. In any case, the timetables prepared by the BSI deliberately left some scope for individual companies to set their own pace. Given the complexities of the problem, and the Government's knack for making simple things sound difficult, all seemed well.

Difficulties started to arise when the Confederation of British Industry submitted a report to the Joint Committee on Metrication which suggested the formation of a Metrication Board, similar in status and function to the Decimal Currency Board. 'The CBI evidently wanted to do two things-help those industries which still had doubts about the wisdom of the change, and help to organize the change in the retail sector. Unlike most countries, Britain had decided that the change to metric units in the shops should follow rather than precede the change in industry. There was some danger, the CBI felt, that the change in the retail sector would be left until too late, and that the best way of avoiding this was to set up a strong Metrication Board. The Standing Joint Committee on Metrication accepted the logic of this recommendation, and a month ago had prepared a report which embodied the CBI's idea as its principal recommendation. Nobody questioned the urgency of the report.

But this was a month ago. Since then, nothing seems to have happened-the Standing Joint Committee's report has not been published, and no statement of Government intentions has been made. A frustrated president of the CBI, Mr Gerry Norman, has now felt obliged to protest in strong terms about the delay. The need for the metrication Board was becoming more and more urgent as time passed, he said, as industry proceeded with its plans for metrication. Publication of the report had become an urgent priority.

There are two possible explanations for this strange breakdown in communications. The first, and least likely, is that the Government has now had cold feet about the whole thing, and wants to postpone the change for a year or so. (It is inconceivable that the Government would want to cancel it altogether.) There has, it is true, been some opposition to the change in some sectors of industry, principally in the building industry, which thinks that the change in standards will permanently increase its costs. Because buildings last very much longer than other manufactured products, the building industry will have to live with dual standards for longer than other industries. The thought of having to fit metric baths into non-metric bathrooms for the next 60 years is admittedly sobering, but hardly overwhelming.

It is in fact far more likely that the delay is simply further evidence of the inability of government in Britain to move quickly, even when all are agreed that speed is essential. No doubt the report of the Standing Joint Committee has been cheerfully circulating around government departments, gathering initials and amendments at every turn. The only explanation offered this week was that the problems of planning machinery and the costs of the change were causing delayalthough it is fair to add that a month in Whitehall passes as quickly as a week elsewhere. The best estimate was that "clarification" could certainly be expected by the end of July, when Parliament rises for the summer recess. This is a dismal performanceand the Fulton Commission, which next week publishes its judgment of the British Civil Service, could hardly have picked a better time.

\section{Good Cheer for Fusion}

Plasma physicists working on the problem of turning thermonuclear fusion into a source of power continue to express a guarded optimism. It is true that controlled fusion is a very long term prospect, but people still think it will be able to compete with other sources of power. One of these is Professor D. J. Rose from Massachusetts Institute of Technology, who has just published the results of work carried out at Oak Ridge National Laboratory during a sabbatical year (report ORNL-TM-2204). Professor Rose, who is spending the rest of his sabbatical at Culham Laboratory, produces hopeful results by proposing very large fusion power stations, of 10,000 electrical megawatts or so. As he points out, power stations this big are unlikely to be needed by most utilities until the twentyfirst century, which is another reason for taking the long view.

Given power stations this size, some of the major difficulties appear to become distinctly more tractable. Professor Rose suggests that plasma containment times only a few times greater than those already achieved in the laboratory would be enough to make a very large fusion reactor economical. Another reason for going to big sizes is that the business part of the fusion reactor is free-it is simply a large evacuated volume in which the fusion reactions between atoms of deuterium and tritium would take place.

Professor Rose's calculations do not apply to only one type of system, and it seems that he is not entirely sure which system will turn out best. Thus the calculations apply equally to open or closed, pulsed or steady state reactors. He assumes that direct conversion is unlikely to be feasible, and has therefore proposed a system in which the fusion reactor is used to provide heat for electricity generation. One of the advantages of the sort of system visualized is that it would have a very short tritium doubling time, because the fast neutrons generated in the reactor would breed further tritium in the "blanket" which surrounds the reactor 
vessel. The tritium doubling time would perhaps be of the order of one year. The reactor would also be a very fruitful source of neutrons, but would produce far less radioactive waste than fission reactors. More recent calculations, Professor Rose says, have shown that fusion reactors would produce one ten thousandth as much overall radioactivity as fission reactors of comparable size. Another advantage is that when fusion reactors are shut down, the total afterheat would be tiny - something like 60 kilowatts for a reactor: of 10,000 to $15,000 \mathrm{MW}$. A large fission reactor, by contrast, may be nominally shut down by insertion of the control rods, but nevertheless goes on producing very large quantities of heat-perhaps 10,000 times as much as the fusion reactor the same size.

One of the important results of Professor Rose's report (apart from sustaining optimism among plasma physicists, which is itself important) may be to redirect some of the research effort. Professor Rose is particularly keen that more work should be done on the effects of the energetic neutrons on the reactor vessel. There is no experience of radiation damage at these extreme energies. There is also the question of injecting fuel into the reactor, which may turn out to be a great deal harder than it sounds. But Professor Rose concludes that a fusion power station, if feasible, would be cheap. Capital costs in the region of $£ 12$ per kilowatt and a generating cost of 0.3 pence per kilowatt look good. By the year 2000, of course, there is always the chance that they will have been overtaken by something even better.

\section{Steady State Supported}

THE steady state theory of cosmology still has a great deal of life in it, according to Professor Fred Hoyle, director of the Institute of Theoretical Astronomy at the University of Cambridge. Professor Hoyle, giving this year's Bakerian Lecture at the Royal Society last week, discussed how the evidence put forward against the steady state theory can be overcome. He emphasized, however, that his lecture - a review of recent. developmonts in cosmology - was an entirely personal view of the subject. His interpretation of counts of radio sources, for example, certainly differs from that of several other astronomers.

The most recent challenge to the steady state theory, Professor Hoyle said, was the discovery about three years ago of the microwave background radiation. This is radiation at microwave frequencies which seems to permeate space and corresponds to a black-body temperature of about $3^{\circ} \mathrm{K}$. One school of thought believes the microwave radiation is a by-product of events early in the history of a so-called big-bang universe. One of the reasons for this interpretation is the difficulty in understanding the radiation in terms of emission from existing radio sources which are not expected to emit strongly enough at short wavelengths to account for the measured intensities. The microwave background has consequently been widely held to be a fossil relic of a big-bang cosmology. Professor Hoyle said, however, that there is evidence coming to light that the spectra of an appreciable fraction of radio sources have an upturn toward higher frequencies. This means the microwave background may yet be explained by emission from radio sources, and that the steady state theory will be upheld in this respect.
In his lecture, Professor Hoyle went through the crises the steady state theory had so far faced. In particular, he discussed the way in which counts of radio sources can distinguish between different cosmologies. The practice is to count the number of radio sources $N$ brighter than a certain flux $S$, and to plot $\log N$ against $\log S$. Various cosmologies predict different values for the slope of the straight line through the points, the steady state theory predicting a slope of -1.5 , for instance. Professor Hoyle said that counts of radio sources in the Cambridge $4 C$ and $5 C^{\prime}$ surveys agree with the steadr state cosmology. but that the earlier $3 C$ survey gives a steeper slope more in keeping with the big-bang theory. To understand the steep slope given by the $3 C$ survey in terms of the steady state cosmology, the radio sources making up the surver can be classified according to their appearance and the slope of the $\log N$-log $S$ curve evaluated for each class. Objects which look like radio galaxies lead to a slope of $-1 \cdot 4$. and sources identified as quasars have a slope of -1.56 . The remainder of sources in the $3 C^{r}$ survey, which could not definitely be identified as quasars or as radio galaxies, contributed a slope of $-2 \cdot 5$. Professor Hoyle says the disagreement of the $3 C$ surver with the steady state theorv can thus be attributed to the contribution to the counts of sources the nature of which is unknown, and which therefore may have no cosmological significance. New counts of radio sources now under way in the southern hemisphere may help to resolve this question.

Another criterion for distinguishing cosmologies involves the red-shift of distant objects. The technique is to compare the observed relation between red-shift. and visual magnitude with the relation expected for various cosmologies. All cosmologies predict the same relation between red-shift and visual magnitude for comparatively local objects, however, and it was not until the discovery of the quasars, with their large red-shifts, that red-shifts could be used by cosmologists in this way. Although measurements of quasars tend to support the big-bang theory, there is doubt whether their large red-shifts are in fact of cosmological significance at all. The problem seerns to hinge around indications that quasars are large masses confined in volumes comparatively small by astronomical standards. This suggests that their large red-shifts may be a gravitational effect, yet the spectra of quasars are not what are expected for emission in a high gravita. tional field. Further, some quasars seem to show more than one red-shift, and up to nine red-shifts have been associated with one object. This may mean the emission is coming from differing positions in a strong gravitational field, or an alternative explanation is that the quasar is ejecting clouds of gas at speeds approaching the speed of light. The uncertainty about what quasars really are makes their cosmological significance much less convincing.

\section{Daresbury's Plan}

The Nuclear Physics Laboratory at Daresbury sees as one of its functions the design of accelerators which may form the future development of the sitc. At the moment, for example, the Daresbury laboratory is completing a design study for an electron synchrotron producing energies which may go up to $20 \mathrm{GeV}$. One of the features of the Daresbury design is that it uses 